Australian Journal of

Crop Science

AJCS

AJCS 14(03):439-446 (2020)

ISSN:1835-2707

doi: 10.21475/ajcs.20.14.03.p1976

\title{
Sustainable crop production to ensuring food security under climate change: A
} Mediterranean perspective

\author{
Akbar Hossain*1 ${ }^{1}$, Ayman EL Sabagh*285, Celaleddin Barutcular ${ }^{3}$, Rajan Bhatt ${ }^{4}$, Fatih Çiğ ${ }^{5}$, Seyithan \\ Seydoşoğlu ${ }^{5}$, Nizamettin Turan ${ }^{5}$, Omer Konuskan ${ }^{6}$, Muhammad Aamir Iqbal $^{7}$, Magdi Abdelhamid ${ }^{8}$, Cecilia M. \\ Tojo Soler ${ }^{9}$, A.M. Laing ${ }^{10}$, Hirofumi Saneoka ${ }^{11}$ \\ ${ }^{1}$ Bangladesh Wheat and Maize Research Institute, Dinajpur-5200, BANGLADESH \\ ${ }^{2}$ Department of Agronomy, Faculty of Agriculture, Kafrelsheikh University, 33516, EGYPT \\ ${ }^{3}$ Department of Field Crops, Faculty of Agriculture, Cukurova University, TURKEY \\ ${ }^{4}$ Scientist (Soil Science), Regional Research Station, Kapurthala, Punjab Agricultural University, Ludhiana, Punjab, INDIA \\ ${ }^{5}$ Department of Field Crops, Faculty of Agriculture, Siirt University, TURKEY \\ ${ }^{6}$ Department of Field Crops, Faculty of Agriculture, Mustafa Kemal University, Hatay, TURKEY \\ ${ }^{7}$ Department of Agronomy, Faculty of Agriculture, University of The Poonch Rawalakot (AJK), Pakistan \\ ${ }^{8}$ Botany Department, National Research Centre, 33 Al Behoos Street, Dokki, Cairo, EGYPT \\ ${ }^{9}$ Senior Cropping Systems Modeler, Agronomy R \& D - Farmers Edge, Minnesota, USA, CEL 608-260-5707 \\ ${ }^{10}$ CSIRO Agriculture and Food, Brisbane, AUSTRALIA \\ ${ }^{11}$ Graduate School of Biosphere Science, Hiroshima University, 1-4-4 Kagamiyama, Higashi-Hiroshima, 739-8528, JAPAN
}

Corresponding authors: ayman.elsabagh@agr.kfs.edu.eg; akbarhossainwrc@gmail.com

Abstract

\begin{abstract}
The global population is predicted to expand to 9.1 billion by 2050. Countries around the Mediterranean Sea are predicted to achieve a combined population of 529 million by 2025 . The current major challenge confronting sustainable agriculture in the Mediterranean region is climate change which has directly affected the extent and frequency of rain events, floods, and droughts, which in turn has influenced land and water productivity and farmers' livelihoods. The present review highlights the major consequences of climate change for sustainable crop production in the Mediterranean region and evaluates different mitigation strategies for improving agricultural land productivity and water use efficiency along with their impact on farmers' livelihoods.
\end{abstract}

Keywords: Climate change, Food security, Mediterranean region, Sustainable agriculture

Introduction

Continued global population growth increase will require an increase of $70 \%$ of food production over the next 30 years, particularly in developing countries (FAO, 2013). To meet this increasing food demand and to remain self-sufficient, countries need to increase domestic agricultural production. To sustainably produce more food all stakeholders in food value chains need to work together and according to a new common agricultural policy specially designed to cope with increasing climate variability and change (Reisch et al., 2013; Candel et al., 2014).

The population of countries around the Mediterranean is increasing by $1.35 \%$ per year, growing from 412 million in 2000 to 466 million in 2010, from a base of 276 million in 1970 . If the present growth rate continues, population will increase to 529 million by 2025 . Four countries in the Mediterranean region encompass about $60 \%$ of the total population: Turkey, Egypt, France and Italy, which have 81, 72, 62 and 60 million people, respectively (UNDESA, 2011). The population is concentrated in coastal regions, and more than $50 \%$ of people live on the southern shores of the Mediterranean Sea (UNEPA/MAP/MEDPOL, 2005).) (Figure 1).

Much of the climate around the Mediterranean is arid or semiarid and in consequence agriculture in the region is affected by climate, in particular high temperatures and drought.

Constraints to sustainable crop production in the Mediterranean environment

Climate change affects agricultural production globally (Godfray et al., 2010). Scientists and policymakers around the 
world have warned that if action is not taken to mitigate existing levels of greenhouse gas emissions and reduce future emissions then future food production and food security will be at risk (Scherrer et al., 2005). Much research has already been conducted to quantify and mitigate the effects of the changing climate on agricultural production (Ali et al., 2017; Lobell and Field, 2007). An estimation showed that $60 \%$ of global land productivity is adversely affected by climate change (Ray et al., 2015) leading to threats to food security which are exacerbated by increasing human population (Gornall et al., 2010; Hillel and Rosenzweig, 2010). The IPCC (2007) estimates that average global air temperatures will increase by $0.2^{\circ} \mathrm{C}$ decade $^{-1}$ which will lead to an increase in average temperatures of between 1.8 to $4.0^{\circ} \mathrm{C}$ by the year 2100 . Seo and Mendelsohn (2008) observed a considerable yield loss in major crops due to rising temperatures and decling precipitation (i.e. increased occurrence of drought) in semiarid environments. They also demonstrated that heat and drought stresses generally occurred simultaneously in arid and semi-arid agricultural environments (e.g. Mediterranean regions).

\section{Mitigation strategies to face agronomic challenges in crop production in the Mediterranean environment}

In most of the Mediterranean countries, agriculture is one of the larger contributors to the economy, contributing $20 \%$ of the gross net product (GNP) in the south-Mediterranean countries (Hervieu, 2008). Agricultural lands in most of the countries in the southern Mediterranean are arid and semiarid, and crop productivity is highly susceptible to climate change. Consequently, local food supply is of great concern in this region. In the arid and semiarid areas of the Mediterranean countries farmers generally use improved dryland farming techniques for sustainable crop production. It is imperative to understand the likely effects of changing climatic conditions on agricultural production in order to meet the food security needs of increasing human populations.

Globally, nearly $74 \%$ of crops are cultivated under rainfed (often water-stressed) conditions, and this is particularly the case in the arid and semiarid regions of the southern Mediterranean (Birard et al., 2009). Approximately $26 \%$ of global agricultural lands are irrigated (World Bank, 2008). Limited water supply for irrigation is a key constraint which reduces crop production in arid and semiarid regions (Iglesias et al., 2007, 2009). Additionally, other factors such as planting time, crop-weed competition, diseases, pests, nutrient deficiencies, abnormal edaphic conditions including salinity, and high or low temperature stresses may also contribute to lower crop productivity (Angus and van Hearwardeen, 2001; Grassini et al., 2009). Besides these, the lack of locallyappropriate crop varieties which are tolerant to biotic and abiotic stresses is a great constraint in the southern Mediterranean region.

Therefore, future research should include a focus on improving the production potential of different crops in water-stressed conditions and on texturally divergent soils under diverse ecological conditions (Murat and Stephen, 2006). Current research is addressing some of these concerns, including developing improved resource conservation technologies to increase soil water accumulation and water holding capacity; decreasing runoff and evaporation or evapotranspiration loss; breeding and selecting appropriate crop species/genotypes which are able to make more efficient use of rainwater; promoting targeted and balanced fertilizer usage; improving crop management to optimize available soil moisture and judicial weed and pest management. In this paper we provide a detailed description of mitigation strategies to limit the adverse effect of climate change and provide opportunities for sustainable agricultural production in the southern Mediterranean environment.

\section{Organic matter management in dryland cropping systems}

The soil organic matter (SOM) is the main factor which determines its physicochemical and biological properties, on which the land and water productivity of soil depend. Increasing SOM increases the water holding capacity and reduces runoff and soil erosion in dryland cropping systems, particularly in southern Mediterranean environments. Up 65 to $75 \%$ of the total SOM is humus. SOM also increases the cation exchange capacity along with influencing soil microbial activities which lead to increased productivity in growing plants (Pettit, 2006). .

In dryland farming systems, due to a general scarcity of rainfall, cattle numbers are low and subsequently the application onto cropland of farmyard manure is not common and does is not a large source of organic matter in soils. Retaining crop residues on the field surface as a mulch insulates soil temperatures from extremes of heat or cold, and reduces soil moisture loss (Bhatt and Khera, 2006; Ward et al., 2009). O'Leary and Connor (1997) found that increasing crop residues in dryland cropping systems improved the soil water balance and water permeability through the soil while reducing soil water evaporation,-surface runoff, surface compaction particularly in clay soils, and soil erosion (Foley and Silburn 2002). Improved management of crop residues and SOM increases the presence of soil water as a result of increased soil roughness which reduces the speed at which water runs off. This change in soil texture also reduces erosion, even on steep soils (Paustian et al., 2000). Furthermore, mulching with crop residues further reduces erosion, even under heavy rains, by reducing the speed at which water runs off, while concurrently reducing losses through evaporation and promoting transpiration. These benefits ultimately increase land productivity within semi-arid and arid regions such as that of the southern Mediterranean (Anderson, 2009; Eberbach et al., 2011).

\section{Fertilizer management in dryland cropping systems}

A key contributor to low crop production in many arid and semi-arid environments is deficiency in soil macro- and micronutrients, in particular the macronutrients nitrogen $(N)$, phosphorus $(\mathrm{P})$ and potassium $(\mathrm{K})$. To improve crop production fertilizer management practices based on locally analysed soil nutrient levels should be incorporated into best practice agronomic management packages (Dregne, 2011). 
Fertilizer is important to facilitate plant growth, including the plant rhizosphere range which improves the water uptake capacity of growing plants in arid and semi-arid regions. The recommended dose of nutrients applied should consider the accessibility to the plant of the nutrient in the soil and also any potential interaction between applied fertilizers and physical and chemical properties of the soil such as soil $\mathrm{pH}, \mathrm{SOM}$, rate of soil mineralization, $\mathrm{C} / \mathrm{N}$ ratio, presence of antagonist ions, etc. It is necessary to test any soil to quantify its inherent nutrient supply capacity, which can be matched to the nutrient required by particular crops to produce target yields given current climate and edaphic factors (Mori and Di Mola, 2012). Among the essential plant nutrients, $\mathrm{N}$ plays a vital role in increasing biomass and yield through chlorophyll synthesis, which further increases the assimilation of carbohydrates and the expansion of root systems, and promotes increased water and nutrient uptake from the soil profile (Kirkegaard et al., 1994). The nutrient uptake ability of roots has a positive corelation between available soil moisture and applied nutrients through improving salt concentration for moving nutrient flow through diffusion into the plant roots (Zhong and Shangguan, 2014). Higher intake of water by a crop improves its nitrogen use efficiency, as it reduces the loss of $\mathrm{N}$ through leaching in the soil (Wang et al., 2010). Similarly, P contributes to whole plant growth, particularly in the developing root system and controls translocation and balances of assimilates between vegetative and reproductive processes. Adequate $\mathrm{K}$ in the plant is critical for plant resistance to drought stress, as $K$ regulates the opening of stomata which regulate water loss under stressed conditions. Under drought stress, plants alter their physiological and biochemical processes which decreases their yield productivity (Foyer et al., 2002; Oerke and Dehne, 2004; Cakmak, 2005). Water deficits also restrict the supply of nutrients which leads to reduced root growth and limited ability to access $\mathrm{K}$ which in turn weaken the plant and decrease its tolerance of drought stress. $K$ has a critical role in physiological, biochemical and molecular mechanisms of plants under drought (Wang et al., 2013) and therefore adequate Kfertilization is particularly important in water-stressed conditions to improve water productivity and increase tolerance of drought conditions.

\section{Improved soil tillage systems}

Tillage, the mechanical manipulation of the soil to improve conditions for plant establishment and growth, is also used to reduce soil weed banks and to improve soil texture and structure, particularly in dryland farming conditions (Turner, 2004; Bouman, 2007). Systems of reduced or minimum tillage, have a more positive impact on soil health and are better able to preserve soil structure. These systems include strip tillage, minimum and no- or zero-tillagetillage, and raised bed planting (Unger and McCalla, 1980; Erenstein et al., 2008; Holland, 2004). Minimum tillage disrupts only the top $5 \mathrm{~cm}$ of soil and directly sows the seed concurrently with the tillage; generally the soil is not disturbed prior to crop establishment. Minimum tillage can save up to $70 \%$ of the energy required to establish a crop compared with traditional tillage system. The tillage system improves the physical, chemical and biological properties of a soil, thereby improving its productivity (Alam et al., 2014). The appropriate conservation tillage practice must be selected for specific crops (accounting for root system characteristics) and a location's soil physical properties including soil texture, structure, SOM status, and water holding capacity. Conservation tillage systems improve the size of soil aggregates through improving soil structural stability, which has a positive effect on soil health and crop productivity as soil infiltration rates and water holding capacities improve (Perniola et al., 2015). Conservation tillage can be combined with field management along contour lines to promote soil infiltration and reduce runoff and erosion. (Woltering, 2005). However, to have a measurable effect on different physical and chemical soil properties and hence on crop productivity, these techniques must be practiced for at least three to five years (Bhatt and Kukal, 2015; Bhatt and Kukal, 2017 a,b), a fact of which farmers should be made aware before committing to new crop management practices.

\section{Improving surface water retention and sediment control systems}

In the southern Mediterranean region during the springsummer rainfall is very low and, due to poor irrigation networks, water use efficiency is very poor. This has a considerable negative effect on crop productivity. On steeper slopes high levels of erosion contribute to sedimentation in dams and reservoirs which reduces their storage capacity and increases downstream flood risks. The degree of soil erosion depends on the intensity of rainfall and the steepness of the slopes (Lionello et al., 2006).

To minimize erosion-based water losses from agricultural systems it is essential to promote those soil management techniques which promote water infiltration into the soil and which reduce runoff. A three-year study in the hilly Punjab region in India identified the need to initially remove gullies (which collect runoff water) rather than to install expensive check dams (Bhatt and Kukal, 2015). This study also demonstrated that improvements to drainage systems were necessary to control water outflows, flooding and surface runoff losses as well as to reduce evaporation from dryland farming systems. In practice, gentle slopes may be created within fields to promote the slow movement of water before runoff into grassy drainage channels. In a dry environment, land angles/slopes should not be greater than $1 \%$ and fields should as wide as possible (e.g. $30-50 \mathrm{~m}$ ) to increase the time water flows over the soil surface and, consequently, increase water infiltration and retention (Sophocleous, 2002; Brabec et al., 2002; Pimentel et al., 2004). The objective is to decrease 


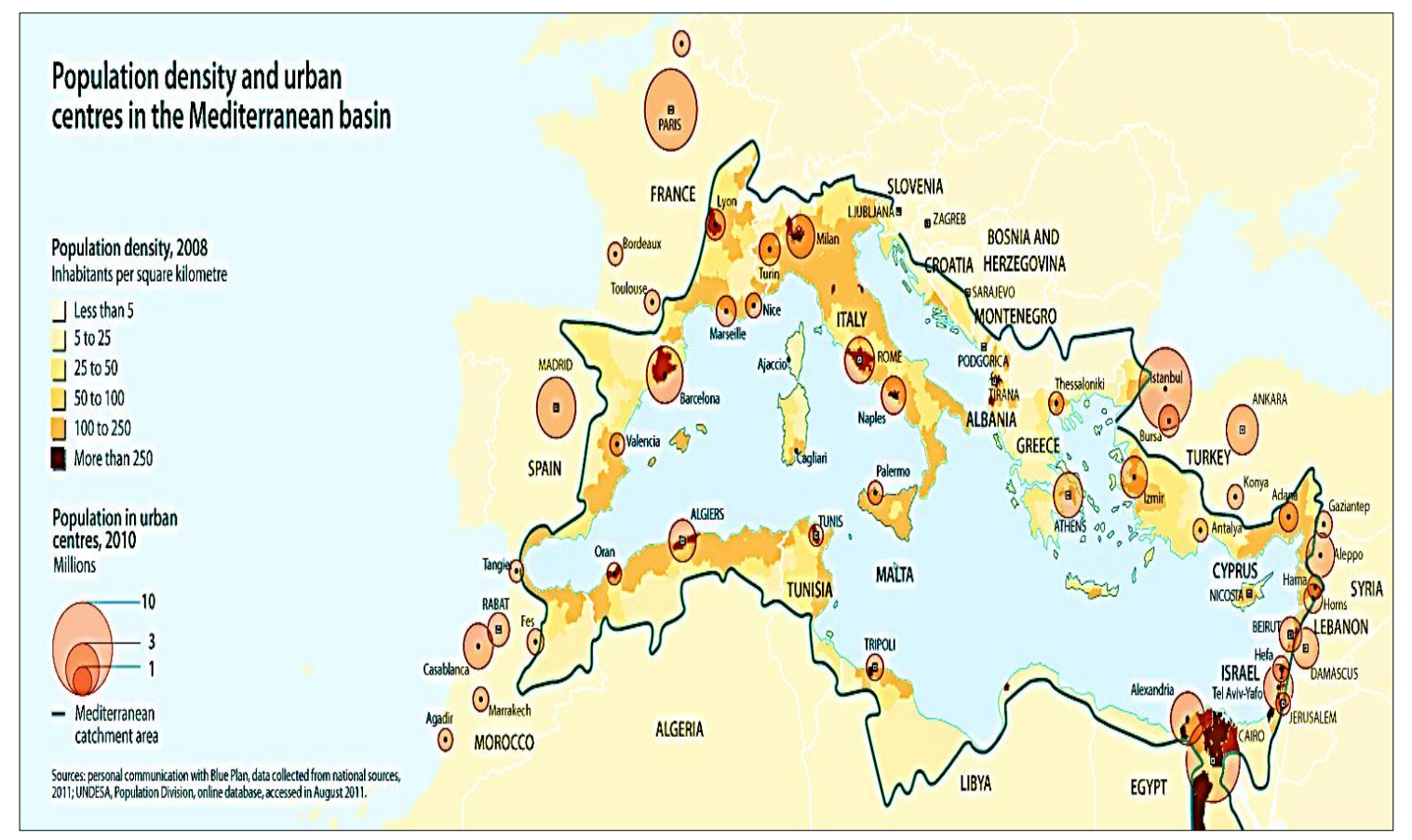

Fig 1. Population density and urban centers in the Mediterranean basin. Source: (UNDESA, 2011).

erosion, thus decreasing the silt deposited into dams and reservoirs and reducing downstream flood risks.

Bare fields are at high risk of erosion and therefore retention of cover is important to reduce runoff, particularly on steep slopes. Terracing may not be viable for cereal crops; in these cases land may be graded to control water runoff and erosion into dedicated channels. These channels should themselves be determined according to soil texture and slope to reduce erosion. The rate of water infiltration into soil primarily depends on the presence and distribution of macropores with a diameter between 30 to $500 \mu \mathrm{m}$ (Pagliai, 1986)

\section{Crop management}

A detailed description of crop management strategies to mitigate adverse effects of climate change and to promote sustainable agricultural production in the southern Mediterranean environment are described below.

\section{Suitable crop cultivars}

In southern Mediterranean environments, low precipitation and high-temperatures are the major abiotic stresses that reduce agricultural production (Bassu et al., 2009). For sustainable crop production, crops should be selected based on the length of the crop growing and the capacity of the variety to achieve relatively high productivity under limiting conditions. For example, in the arid south Mediterranean environment, the growing season of most dryland crops viz., rye, barley, oats and wheat, has been adapted accommodate cold winters followed by water-limited periods until harvest. Of all crops, rye, barley and oats are better adapted to low temperatures and water stress than is wheat (Cossani et al., 2009). In arid conditions, shorter duration crops are preferred as they required less water over their life cycle.

There are two ways to mitigate the adverse effect of limited rainfall and extreme temperatures on crop plants: through the development of new varieties which better tolerate stressful environments; the identification of improved management practices for sustainable crop production under stress conditions (Hossain and Teixeira da Silva, 2013). Over the last three decades, plant breeders have produce new cultivars with stress genes which have higher water use efficiencies under water deficit condition (Hsiao et al., 2007). Hsiao et al. $(1993 a, b)$ and Blum (2005) demonstrated that high-yieldpotential crop varieties could maintain a high water use efficiency in both well-watered and in drought conditions, compared to traditional varieties. Although the ongoing development of new varieties is possible through conventional breeding programs, advances in biotechnology and genetic engineering may provide other avenues for the development of stress-tolerant varieties.

\section{Adjustment of sowing date}

Date of sowing is one of the important agronomic management strategies for grain production. Crop varieties should be selected based on crop season length. In south Mediterranean environments, autumn-winter crops such as durum and spring wheats, barley, oats, and rye are most common as they are grown when maximum moisture is available (Laux et al., 2010). The optimum sowing time of a crop facilitates its growing under maximum rainfall while reducing exposure to thermal stresses at the onset of the hot 
season (Hossain et al., 2012a,b). While the Indian Punjab region does not have a Mediterranean climate, it is also an arid region from which much water is used to cultivate (basmati) rice. In this region traditionally farmers sowed rice seedlings in May, which is a time of great heat and evaporative demand, and requires high irrigation. $\mathrm{R}$ It has been suggested that delaying crop establishment from May to June (which is associated with the onset of the monsoon) would result in reduced irrigation as evaporative demand would be lower. This change would increase irrigation water productivity throughout the Indian Punjab, and also reduce exposure to early-season rice pests which also adversely affect yield.

\section{Weed management}

Weeds compete with crop plants for water, nutrients and sunlight (Bhatt and Kukal, 2017a,b). Weed management is critical point for sustainable crop production in all environments, including the southern Mediterranean. In this region, many common cereal crops are negatively affected by weeds outcompeting them for water, light, nutrients, and space (Barros et al., 2008). Additionally, weeds also adversely affect the qualitative characteristics of crops which leads to deteriorated yield quantity and quality (Weiner et al., 2001; 2010). Therefore, for sustainable crop production, weeds should be controlled through preventive and preferably nonchemical agronomic procedures including crop rotations with weed-cleaning crops; selecting crop varieties which grow faster than weeds; by growing crops at a slightly higher plant density than recommended to reduce available space for weeds; thorough preparation of the seedbed to germinate and kill weed seedlings; and timely intervention with mechanical weeders at early crop growth stages. Control of weeds with herbicides has environmental and health risks and may not be economically viable. Chemical herbicides application should be triggered based on the amount of weeds present and their potential damage to the crop, to ensure applications are economically viable (Barros et al., 2008; Weiner et al., 2001; 2010; Flower et al., 2012). Under zero tillage, significantly higher weed population may be observed, because of surface weed seeds (which get higher sunlight and water/nutrients to proliferate) (Bhatt and Kukl, 2017a,b).

\section{Water-efficient techniques for crop production in dry areas}

Several effective irrigation strategies to optimize water use efficiency, thereby increasing economic and environmental benefits and promoting sustainable crop production have been suggested by, for example Delirhasannia et al. (2010), Sadeghi et al. (2015) and Bhatt and Kukal, (2017a,b). A detailed description of water saving technologies to mitigate adverse effects of climate change and to promote sustainable agricultural production in the southern Mediterranean environment is described below.

\section{Traditional water-saving technologies}

Age old irrigation practices including border, furrow and surface irrigation systems, are of limited water use efficiency but are still being practiced by many farmers in the southern
Mediterranean region. These techniques have been widely adopted they are economical and can be used by farmers with little technical knowledge or access to the latest technology (Blanke et al., 2007). In the furrow irrigation system crops are planted on raised ridges between furrows through which irrigation water flows. Wang et al. (2004), Li et al. (2004) and Darouich et al. (2017) found that furrow irrigation systems increased water productivity as well as wheat yields as compared to more water-intensive flood irrigation. For border irrigation, the field is well-levelled to allow the uniform spread of the applied irrigation water. This system will facilitate water infiltration, reduce runoff and erosion while increasing crop yields (Deng et al., 2004). Surface irrigation is performed using hose-pipe which is used to transport irrigation water to farmers' fields. Zuo (1997) found that piping water under the soil surface could reduce water wastage by $30 \%$ which was of considerable benefit to smallholder farmers with fragmented landholdings. Additional crop management practices including direct seeding of rice, permanent beds, laser levelling, soil matric potential-based irrigation, and underground irrigation pipes may be used to advantage in water deficit regions including the southern Mediterranean.

\section{Water saving technologies at a farm level}

Farm-based water saving tools include plastic sheeting, drought resistant crop varieties, use of minimal or no tillage and surface level irrigation piping. These tools are common and can be easily adapted to different household requirements, due to comparatively low costs of implementation. They are also more portable than traditional approaches. For example, rice production systems which use plastic ground covers to reduce water loss through evaporation can restrict water losses by between 50 and $90 \%$ (Abdulai et al., 2005). Additionally, this practice increases soil temperature which facilitates earlier planting and thus earlier harvesting, increasing both crop yield and water use efficiency (Li et al., 2003).

\section{Community-based water-saving technologies}

Generally, community-based technologies are likely to conserve more water than household-level technologies. These water saving technologies are linked to underground aquifers, which are in turn connected to water bodies such as a rivers, sea or canal. These underground aquifers and lined above-ground canals are made of cement, metal, plastic or any other relatively impermeable material to reduce the water that seeps through the aquifer into the surrounding soil during conveyance from the water source to the field, for irrigation (Cai et al., 2003).

Sprinkler irrigation systems are one type of community-based irrigation technologies, which have a huge fixed cost. These irrigation systems require substantial water pressure to operate and need a community or a group of farming families to operate them in common in order to be economically viable (Zuo, 1997; Peterson and Ding, 2005). Another communitybased water-saving technology is laser levelling. In the Indian states of Punjab and Haryana scientists have demonstrated 
many water-saving technologies to farmers, however it is laser levelling which is of most interest to farmers and which has been adopted throughout these states as levelling considerably improves water use efficiency, enables the irrigation of larger areas in shorter time and finally improves farmers' crop productivity.

\section{Conclusion}

Water scarcity in the arid and semi-arid environment of the southern Mediterranean is one of the major challenges for sustainable crop production. The challenge of producing crops with limited water is expected to further worsen under climate change. The consequences of climate change for the southern Mediterranean region which have been identified in this study will serve as reference for developing new technology packages and well as policies to promote and facilitate sustainable crop production in the region. This will enable smallholder farmers to mitigate some of the climate-based challenges of future crop production and to meet the increasing food demand of a growing regional population. In particular we have identified the selection of short duration cultivars, and the introduction of mulching, laser leveling, tensiometer-based irrigation management, mechanical transplanting of rice, and permanent crop beds as likely crop management methods to assist in improving water productivity and crop production for smallholder farmers in the arid and semi-arid regions of the southern Mediterranean.

\section{Conflict of interest}

Authors declared no conflict of interest.

\section{Disclaimer statement}

We hereby declare that all co-authors of the review have seen and approved the final version before submission. The content of the chapter has not been submitted somewhere else nor is it being considered for publication elsewhere. We also declare that this chapter contains no material for publication in any publishers, except where due reference is made in the text.

\section{Reference}

Abdulai A, Thomas G, Thomas, H, Shudong Z (2005) Water Saving Technology in Chinese Rice Production. Evidence from Survey Data. Working paper.

Alam MK, Islam M, Salahin N, Hasanuzzaman M (2014) Effect of tillage practices on soil properties and crop productivity in wheat-mungbean-rice cropping system under subtropical climatic conditions. The Scientific World Journal. Article ID 437283, 15 pages

Ali S, Liu Y, Ishaq M, Shah T, Ilyas A, Din I (2017) Climate change and its impact on the yield of major food crops: Evidence from Pakistan. Foods 6(6): 39

Anderson G (2009) The impact of tillage practices and crop residue (stubble) retention in the cropping system of Western Australia. Oxford: Department of Agriculture and Food. Bull No. 4786, pp. 93.
Angus JF, van Hearwardeen AF (2001) Increasing water use and water use efficiency in dryland wheat. Agron J. 93: 290-298.

Barros JF, Basch G, de Carvalho M (2008) Effect of reduced doses of a post-emergence graminicide to control Avenasterilis L. and Loliumrigidum G. in no-till wheat under Mediterranean environment. Crop Protect. 27(6): 10311037.

Bassu S, Asseng S, Motzo R, Giunta F (2009) Optimising sowing date of durum wheat in a variable Mediterranean environment. Field Crops Res. 111(1-2): 109-118.

Bhatt R, Kukal SS (2017a) Tillage and establishment method impacts on land and irrigation water productivity of wheatrice system in north-west India. Exp Agric. 53(2):178-201.

Bhatt R, Kukal SS (2017b) Soil evaporation studies using minilysimeters under differently established rice-wheat cropping sequence in Punjab, India. J Appl Nat Sci. 9(1): 222-9.

Bhatt R, Kukal SS (2015) Dynamics of gully erosion in lower Shiwaliks. J Soil Water Conserv. 14(1): 1-9.

Bhatt, R, Khera, KL (2006) Effect of tillage and mode of straw mulch application on soil erosion losses in the submontaneous tract of Punjab, India. Soil Tillage Res. 88: 107115.

Birard CM, Thenkabail PS, Noojipady PLY, Dheeravath V, Turral H, Velpuri M, Gumma MK, GalganakuntaORP, Cai XL, Xiao X, Shull MA (2009) A global map of rainfed cropland areas at the end of last millennium using remote sensing. Int J Appl Earth Observ Geoinform. 11:114-129.

Blanke A, Rozelle S, Lohmar B, Wang, J, Huang, J (2007) Water saving technology and saving water in China. Agric Water Manag. 87(2): 139-50. doi.org/10.1016/j.agwat.2006.06.025.

Blum A (2005) Drought resistance, water use efficiency and yield potential-are they compatible, dissonant or mutually exclusive? Aust J Agric Res. 56:1159-1168.

Bouman BAM (2007) A conceptual framework for the improvement of crop water productivity at different spatial scales. Agric Syst. 93(1-3): 43-60.

Brabec E, Schulte S, Richards PL (2002) Impervious surfaces and water quality: a review of current literature and its implications for watershed planning. J Plann Liter. 16(4): 499514.

Cai X, Rosegrant, M, Ringer C (2003) Physical and economic efficiency of water use in the river basin: Implications for efficient water management. Water Resour Res. 39(1): 1013.

Cakmak I (2005) The role of potassium in alleviating detrimental effects of abiotic stresses in plants. J Plant Nutr Soil Sci. 168: 521-530.

Candel JJ, Breeman GE, Stiller SJ, Termeer CJ (2014) Disentangling the consensus frame of food security: The case of the EU Common Agricultural Policy reform debate. Food Policy. 44:47-58.

https://doi.org/10.1016/j.foodpol.2013.10.005

Cossani CM, Slafer GA, Savin R (2009) Yield and biomass in wheat and barley under a range of conditions in a Mediterranean site. Field Crops Res. 112(2-3): 205-213.

Darouich H, Cameira M, Gonçalves J, Paredes P, Pereira L (2017) Comparing sprinkler and surface irrigation for wheat using multi-criteria analysis: Water saving vs. economic returns. Water 9(1), p.50. 
Delirhasannia R, Sadraddini AA, Nazemi AH, Farsadizadeh D, Playán E (2010) Dynamic model for water application using centre pivot irrigation. Biosyst Eng. 105(4): 476-485.

Deng X-P, Lun S, Heping Z, Neil CT (2004) Improving Agricultural Water Use Efficiency in Arid and Semiarid Areas of China.New Directions for a Diverse Planet. Proceed 4th Int Crop Sci Congr. 26 Sep. to 1 Oct 2004, Brisbane, Australia (www.cropsceince.org.au). 2004.

Dregne HE (2011) Soils of arid regions. Development in Soil Science (Vol. 6).Elsevier Scientific Publishing Company, Amsterdam, Netherlands. pp. 236.

Eberbach PL, Humphreys E, Kukal SS (2011) The effect of rice straw mulch on evapotranspiration, transpiration and soil evaporation of irrigated wheat in Punjab, India. Agric Water Manag. 98(12):1847-1855.

Erenstein O, Sayre K, Wall P, Dixon J, Hellin, J (2008) Adapting no-tillage agriculture to the conditions of smallholder maize and wheat farmers in the tropics and sub-tropics. No-till Farming Syst. 253-278.

FAO (2013) Food Insecurity in the World. FAO publications catalogue.

Flower KC, Cordingley N, Ward PR, Weeks, C (2012) Nitrogen, weed management and economics with cover crops in conservation agriculture in a Mediterranean climate. Field Crops Res. 132: 63-75.

Foley JL, Silburn DM (2002) Hydraulic properties of rain impact surface seals on three clay soils. Aust J Soil Res. 40:10691083.

Foyer C.H., Vanacker H., Gomez L.D., Harbinson J (2002) Regulation of photosynthesis and antioxidant metabolism in maize leaves at optimal and chilling temperatures: Review. Plant Physiol Biochem. 40:659-668.

Godfray HC, Beddington JR, Crute IR, Haddad L, Lawrence D, Muir JF, Pretty J, Robinson S, Thomas SM, Toulmin C (2010) Food security: The challenge of feeding 9 billion people. Science. 327: 812-818.

Gornall J, Betts R, Burke E, Clark R, Camp J, Willett K, Wiltshire A (2010) Implications of climate change for agricultural productivity in the early twenty first century. Philosophical Transactions of the Royal Society B: Biological Sciences. 365(1554): 2973-2989.

Grassini P, Yang HS, Cassam KG (2009) Limits to maize productivity in western corn-belt: a simulation analysis for fully irrigated and rainfed conditions. Agric Meteorol. 149:1254-1265.

Hervieu B (2008) The future of agriculture and food in Mediterranean countries.Presses de la FondationNationale des Sciences Politiques (OFCE).https://www.cabdirect.org/cabdirect/abstract/20093 019945. Accessed on 03 May 2019.

Hillel D, Rosenzweig C (2010) Climate change and agroecosystems: main findings and future research directions ICP Series on Climate Change Impacts, Adaptation, and Mitigation vol1 (Handbook of Climate Change and Agroecosystems Impacts, Adaptation, and Mitigation). Hillel D, Rosenzweig C. (eds.). Imperial College Press, London, UK.

Holland JM (2004) The environmental consequences of adopting conservation tillage in Europe: reviewing the evidence. Agric Ecosyst Environ. 103:1-25.
Hossain A, Teixeira da Silva JA, Lozovskaya MV, Zvolinsky VP, Mukhortov VI (2012b) High temperature combined with drought affect rainfed spring wheat and barley in southeastern Russia: yield, relative performance and heat susceptibility index. J Plant Breed Crop Sci. 4(11): 184-196.

Hossain A, Teixeira da Silva JA, Lozovskaya MV, Zvolinsky VP (2012a) High temperature combined with drought affect rainfed spring wheat and barley in South-Eastern Russia: I. Phenology and growth. Saudi J Biol Sci. 19(4): 473-487.

Hossain A, Teixeira da Silva JA. (2013) Wheat production in Bangladesh: its future in the light of global warming. AoB Plants. 5: pls042. doi: 10.1093/aobpla/pls042

Hsiao TC (1993a) Growth and productivity of crop in relation to water use. Acta Hort. 335:137-148

Hsiao TC (1993b) Effect of drought and elevated CO2 on plant water use efficiency and productivity. In: Black JMB (ed) Interacting stress on plants in changing climate. Springer, Berlin, pp 435-465

Hsiao TC, Steduto P, Fereres E (2007) A systematic and quantitative approach to improve water use efficiency in agriculture. Irrig Sci. 25:209-231.

Iglesias A, Garrote L, Cancelliere A, Cubillo F, Wilhite DA (editors) (2009) Coping with drought risk in agriculture and water supply systems: Drought management and policy development in the Mediterranean. Springer Science \& Business Media, 22 Jan 2009 - Technology \& Engineering. pp. 320.

Iglesias A, Garrote L, Flores F, Moneo M (2007) Challenges to manage the risk of water scarcity and climate change in the Mediterranean. Water Resour Manag. 21(5): 775-788.

IPCC (Intergovernmental Panel on Climate Change) (2007) Climate change 2007-The physical science basis. In Contribution of Working Group I to the Fourth Assessment Report of the Intergovernmental Panel on Climate Change; Cambridge University Press: Cambridge, UK, 2007.

Kirkegaard JA, Gardner PA, Angus JF, Koetz E (1994) Effect of brassica break crops on the growth and yield of wheat. Aust J Agric Res. 45: 529-545.

Laux P, Jäckel G, Tingem RM, Kunstmann H (2010) Impact of climate change on agricultural productivity under rainfed conditions in Cameroon-A method to improve attainable crop yields by planting date adaptations. Agric For Meteorol. 150(9): 1258-1271.

Li FM, Wang P, Wang J, Xu JZ (2004) Effects of irrigation before sowing and plastic film mulching on yield and water uptake of spring wheat in semiarid Loess Plateau of China. Agric Water Manag. 67: 77-88.

Li Y, Shao M, Wang W, Wang Q, Horton R, (2003) Open-Hole Effects of Perforated Plastic Mulches on Soil Water Evaporation. Soil Sci. 168(11): 751-758.

Lionello P, Malanotte-Rizzoli P, Boscolo R, Alpert P, Artale V, Li L, Luterbacher J, May W, Trigo R, Tsimplis M, Ulbrich $U$ (2006) The Mediterranean climate: An overview of the main characteristics and issues, Editor(s): P. Lionello, P. MalanotteRizzoli, R. Boscolo, Developments in Earth and Environmental Sciences, Elsevier, Volume 4: 1-26.

Lobell DB, Field CB (2007) Global scale climate-crop yield relationships and the impacts of recent warming. Environ. Res. 2: 014002. 
Mori M, Di Mola I (2012) Guidaalla Concimazione. Metodi, Procedure e strumenti per unservizio di consulenza. Imago editrices. r. I., Italy

Murat I, Stephen D (2006) An analysis of the impact of climate change on crop yields and yield variability. Appl Econom. 38: 835-844.

O'Leary GJ, Connor DJ (1997) Stubble retention and tillage in a semi-arid environment: 3 response of wheat. Field Crops Res. 54:39-50.

Oerke EC, Dehne HW (2004) Safeguarding production-losses in major crops and the role of crop protection. Crop Prot. 23:275-285.

Pagliai M (1986) Effettidellalavorazione e non lavorazionesullaporosita di un terrenofrancoargillosoinvestito a vigneto. Rivista di Agronomia 20:178-183.

Paustian K, Six J, Elliott ET, Hunt HW (2000) Management options for reducing $\mathrm{CO} 2$ emissions from agricultural soils. Biogeochem. 48(1): 147-163.

Perniola M, Lovelli S, Arcieri M, Amato M., (2015) Sustainability in Cereal Crop Production in Mediterranean Environments. In: Vastola A (ed.), The Sustainability of Agro-Food and Natural Resource Systems in the Mediterranean Basin, (pp. 15-27). Springer, Cham. DOI 10.1007/978-3-319-16357-4_

Peterson JM, Ding Y (2005) Economic Adjustments to Groundwater Depletion in the High Plains: Do Water-Saving Irrigation Systems Save Water? Am J Agric Econom. 87(1):147-159.

Pettit RE (2006) Organic matter, humus, humate, humic acid, fulvic acid, and humin. The Wonderful World of Humus and Carbon.http://www.bestturfwest.com/content/Vi-

Core/Dr._Pettit_Humate.pdf. Accessed on 30 July 2019.

Pimentel D, Berger B, Filiberto D, Newton $M$, Wolfe B, Karabinakis E, Clark S, Poon E, Abbett E, Nandagopal S (2004) Water resources: agricultural and environmental issues. BioSci. 54(10): 909-918.

Ray DK, Gerber JS, MacDonald GK, West PC (2015) Climate variation explains a third of global crop yield variability. Nat Commun. 6: 5989.

Reisch L, Eberle U, Lorek S (2013) Sustainable food consumption: an overview of contemporary issues and policies. Sustainability: Science, Practice and Policy. 9(2): 725.

Sadeghi SH, Peters TR, Amini MZ, Malone SL, Loescher HW (2015) Novel approach to evaluate the dynamic variation of wind drift and evaporation losses under moving irrigation systems. Biosyst Engg. 135: 44-53.

Scherrer SC, Appenzeller C, Liniger MA, Schär C (2005) European temperature distribution changes in observations and climate change scenarios. Geophys Res Lett. 32: L19705.

Seo N, Mendelsohn R (2008) An analysis of crop choice: Adapting to climate change in Latin American farms. Ecol Econom. 67:109-116.

Sophocleous M (2002) Interactions between groundwater and surface water: the state of the science. Hydrogeol J. 10(1): 52-67.
Turner NC (2004) Agronomic options for improving rainfall-use efficiency of crops in dryland farming systems.J Exp Bot. 55(407): 2413-2425.

UNDESA (2011) Personal communication with Blue Plan, data collected from national sources, Population Division, online database, accessed in August 2011.

UNEP/MAP/BP/RAC (2009) The State of the Environment and Development in the Mediterranean 2009. United Nations Environment Programme, Mediterranean Action Plan, Blue Plan Regional Activity Centre, Vallbone.

UNEP/MAP/MED POL (2005) Transboundary Diagnostic Analysis (TDA) for the Mediterranean Sea.UNEP/MAP, Athens.1e228.

Unger PW, McCalla TM, (1980) Conservation tillage systems. Adv Agron. 33(1), p.58.

Wang Q, Li F, Zhao L, Zhang E (2010) Effect of irrigation and nitrose application rates on nitrate nitrose distribution and fertilizer nitrose loss, wheat yield and nitrose uptake on a recently reclame sandy farmland. Plant Soil. 337:325-339.

Wang F, Wang X, Ken S. (2004) Comparison of conventional, flood irrigated, flat planting with furrow irrigated, raised bed planting for winter wheat in China. Field Crops Res. 87: 3542.

Wang M, Zheng Q, Shen Q, Guo S (2013) The critical role of potassium in plant stress response. Int J Mol Sci. 14(4): 73707390.

Ward PR, Whisson K, Micin SF, Zeelenberg D, Milroy SP (2009) The impact of wheat stubble on evaporation from sandy soil. Crop Pasture Sci. 60:730-737.

Weiner J, Andersen SB, Wille WKM, Griepentrog HW, Olsen JM (2010) Evolutionary Agroecology: the potential for cooperative, high density, weed-suppressing cereals. Evol Appl. 3(5-6): 473-479.

Weiner J, Griepentrog HW, Kristensen L (2001) Suppression of weeds by spring wheat Triticumaestivum increases with crop density and spatial uniformity. J Appl Ecol. 38(4): 784-790.

Woltering L (2005) Estimating the influence of on-farm Conservation Practices on the Water Balance: Case of the Mzinyathini Catchment in Zimbabwe. Delft University of Technology, The Netherlands.

World Bank (2008) Agriculture for development. In: World development report. The World Bank, Washington, DC.

Zhong Y, Shangguan Z (2014) Water consumption characteristics and water use efficiency of winter wheat under long term nitrogen fertilization regimes in northwest China. PloS One 9(6): e98850.

Zuo M (1997) Development of water-saving dry-land farming. China Agriculture Yearbook 1996. China Agricultural Press, Beijing China. 1997. English Edition. 